\title{
Familial cirsoid aneurysm of the scalp
}

\author{
G. KHODADAD \\ From the Division of Neurosurgery, University of Pennsylvania School of Medicine, Philadelphia, Pennsylvania, \\ U.S.A.
}

SUMMARY One brother and one sister, of seven siblings, had cirsoid aneurysms of the occipital scalp with underlying skull defects and possible intracranial communication. Another sister had no gross scalp abnormality but radiographs of the skull revealed a small occipital bony defect. This is thought to be the first reported example of familial cirsoid aneurysm of the scalp.

Cirsoid aneurysms of the scalp are rare. They are usually of either congenital or traumatic origin. The congenital form is sometimes present at birth, and may be associated with a red or purple birthmark (Maclachlan, 1839; Norris, 1843; Hewett, 1857; Wacher, 1890; Beaumont, 1897; Ward and Horton, 1940); in most of the cases, however, there is no obvious scalp abnormality at birth. The majority of these aneurysms remain asymptomatic until puberty or the third decade of life. Scalp disfiguration is a common and sometimes the only complaint. Other presenting symptoms are headaches, tinnitus, and occasional bleeding.

The traumatic form develops months or possibly years after a penetrating or non-penetrating scalp injury and causes a clinical picture similar to that of the congenital form (Green, 1827-28; Moore, 1857; Hill, 1870; Maylard, 1900; Power, 1915-16; Elkin, 1946; Amyes and Courville, 1950; Cosman, 1959; Oldfield and Addison, 1962).

It is the purpose of this paper to describe the occurrence of this condition in two and possibly three siblings of a Persian family.

\section{CASE 1}

G., a 15 year old schoolboy, was referred to the Saadi Hospital (Pahlavi University, Shiraz, Iran) on 1 July 1966, complaining of a constant throbbing headache and a troublesome noise, associated with a mass in the back of his head. The headache was generalized but more severe in the occipital region. It had started a few months previously and gradually increased in severity, to the extent that he could not study and carry on with his normal activities. The patient had no history of trauma and did not recall any illness or event associated with the onset of symptoms. His mother had told him that the mass in the back of his head was present at birth.
The general physical examination showed a mass in the occipital region (Figs. 1a and b) located in the midline above the occipital protuberance, measuring $3.5 \times 3 \times 2$ $\mathrm{cm}$. The scalp covering the mass was irregular but normal in colour. Pulsation was visible in the profile view synchronous with the radial pulse. Palpation of the mase revealed a strong thrill and auscultation a harsh bruico Digital compression of the ipsilateral occipital arter and superficial temporal artery individually or togethe did not diminish the intensity of the thrill or the bruit but they were reduced when the compression was applie $\Phi$ bilaterally. The cardiovascular, pulmonary, and centrat nervous systems were all within normal limits. Antere posterior and occipital radiographs of the skull showed midline, vertically-oriented oval-shaped defect in the occipital bone measuring $2 \times 3 \mathrm{~cm}$ (Fig. 2). The margin of the defect was regular and non-sclerotic. Vascular markings were not increased and no other abnormality was noted.

OPERATIVE TREATMENT A horseshoe incision was made in the periphery of the lesion and the scalp elevated urtil the bony defect was exposed. The scalp had abundant thin wall vessels and bled profusely. There were two large vascular structures with a wall similar to that of the intracranial sinuses which connected the base of the scalp mass to the superior sagittal sinus through the occipital defect (Figs. 3a and b). The external diameter of one was $5 \mathrm{~mm}$ and the other $3 \mathrm{~mm}$. There was also a small vessel which crossed the $5 \mathrm{~mm}$ vascular structure and entered theother one. This small vessel had a very thin wall and contained bright red blood. The dura mater at the site of the bony defect appeared normal. The two sinus-like structures were punctured with a small needle and dark blood was obtained. This was after most of the arterial supply to the aneurysm was interrupted, except for the pedicle of the scalp flap. After further dissection these sinus-like structures were doubly ligated and $\sigma$ divided. The divided end of the cranial side was rein- $N$ forced with periosteum and the wound closed. After the $N$ 


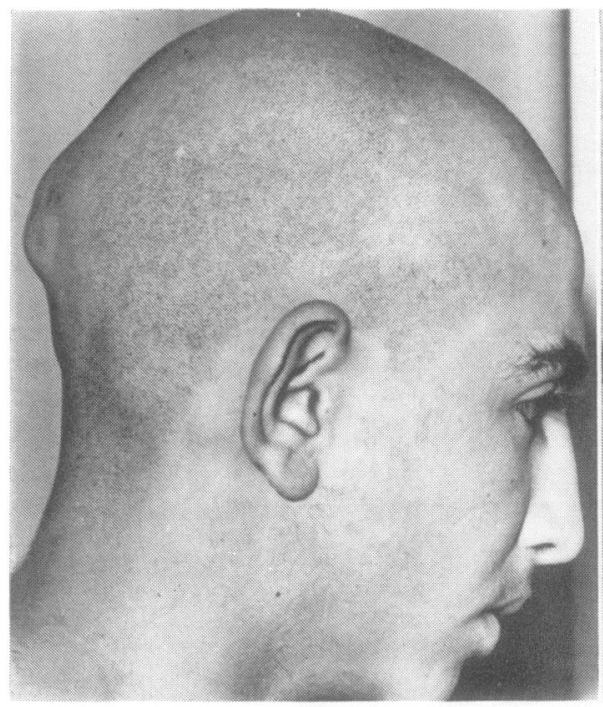

FIG. 1a

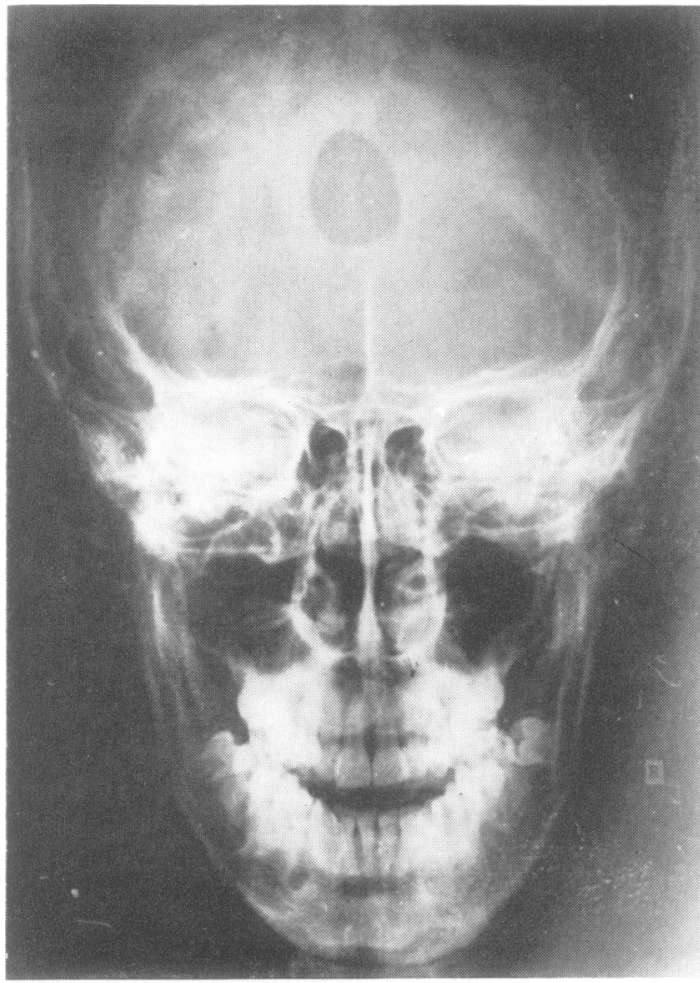

FIG. 2 Case 1.

FIG. 1b

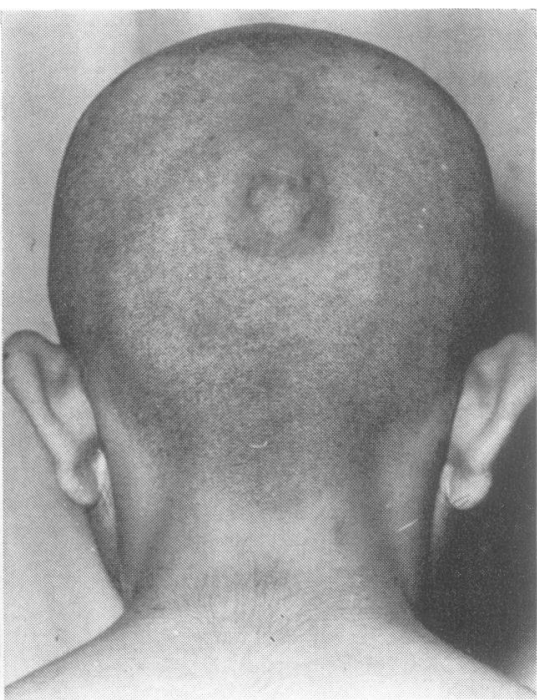

FIG. $1 a, b . \quad$ Case 1 .

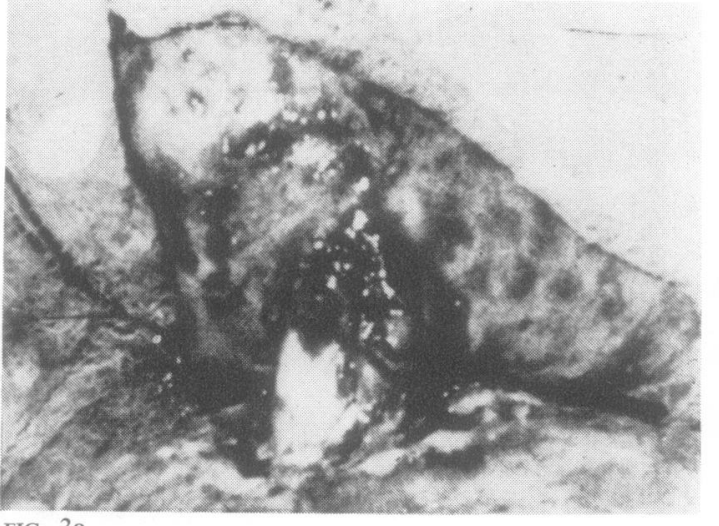

FIG. 3a

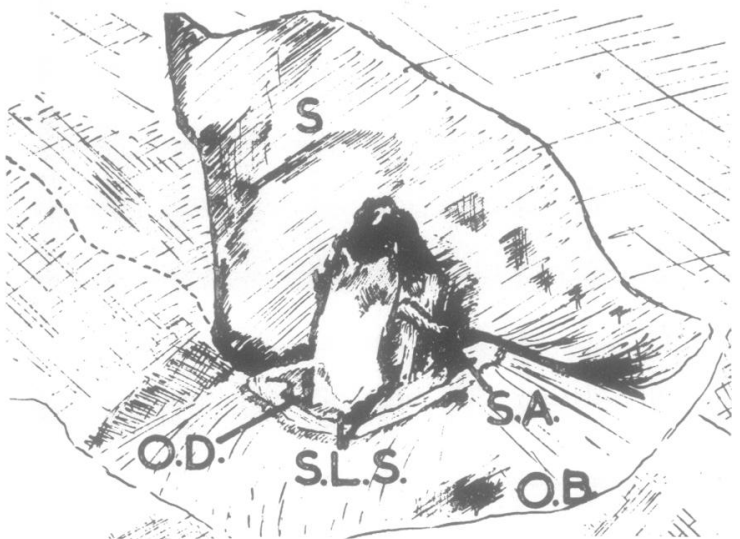

FIG. 3b

FIG. 3a. Case 1. Site of the operation. The scalp flap is elevated and sinus-like structures are isolated. b. Tracing of Fig. 3a showing the scalp (S), occipital bone (O.B.), occipital defect (O.D.), sinus-like structures (S.L.S.), and small artery (S.A.). 
operation the patient was relieved from the headaches and the noise. Eight months later he was still symptom free.

\section{CASE 2}

N., a 26 year old housewife, a sister of patient G., came to the clinic because of a small mass in the back of her head. She had no headaches or tinnitus. Combing her hair or lying flat on her back, however, caused slight discomfort. The most important feature of her past history was that the mass in the back of her head was present at birth and had increased in size.

There was a round and somewhat irregular mass in the mid-occipital region in almost the same location as in her brother. It measured $2.5 \times 2 \times 1 \mathrm{~cm}$. Thrill and bruit were present and both could be diminished when the occipital arteries were compressed bilaterally. The rest of the examination was normal.

Radiographs of the skull revealed an oval-shaped defect in the occipital bone which was located in the midline and measured about $1 \mathrm{~cm}$ in diameter (Fig. 4). Excision was advised but the patient refused.

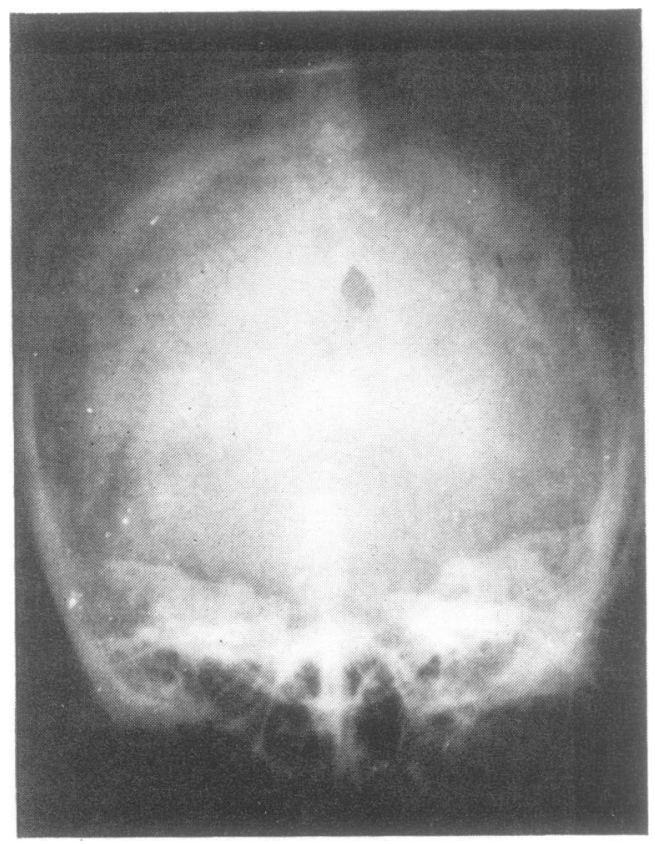

HIG. 4 Case 2.

FAMILY HISTORY The father of both patients had died of pulmonary disease. According to the family he did not have a scalp abnormality, and no radiographs of the skull had been taken. Their mother was 54 years old and in good health. On examination the only abnormal finding was a pedunculated round mass about a centimetre in diameter on the tip of the tongue. It had been present for many years but caused no severe trouble for her. Radiographs of the skull revealed no abnormality.
Excision of the mass was suggested but it was refused. Apart from case 2, there were five other sisters in the family. Four of them were not available for examination. The family, however, stated that none of them had an obvious scalp abnormality. The remaining sister, B. (case 3), a 36 year old housewife, was examined and no abnormality was found. Radiographs of the skull, nevertheless, demonstrated a small hole in the occipital bone in the midline and about $2.5 \mathrm{~cm}$ from the lambda (Fig. 5). Physical examination and skull radiographs of this patient's daughter, who was 8 years old, were normal.

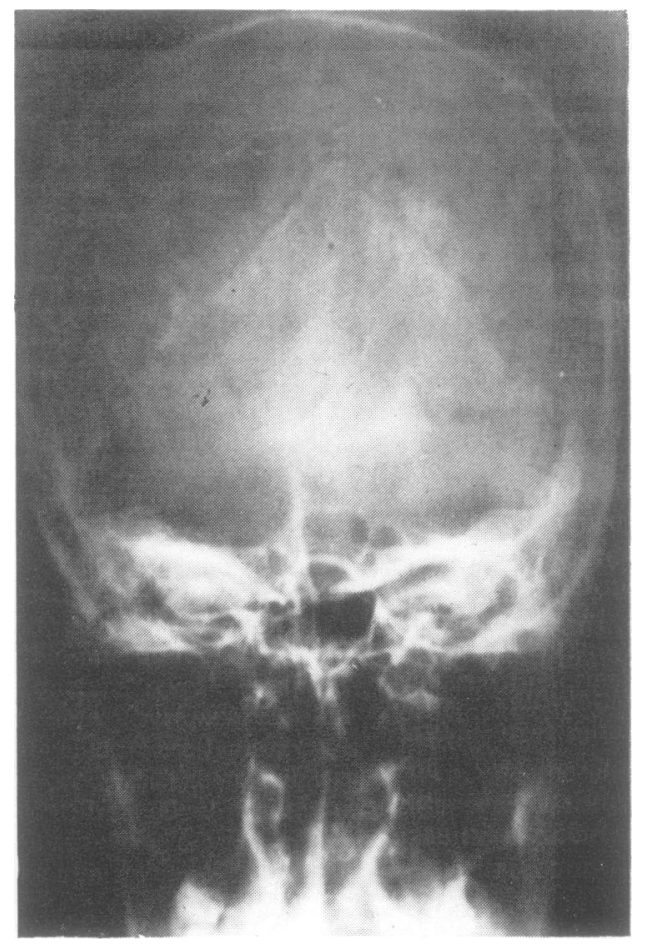

FIG. 5 Case 3.

\section{DISCUSSION}

Review of the literature failed to reveal a report of $\frac{0}{0}$ familial cirsoid aneurysms of the scalp. Tonnis and Lange-Cosack (1953) have reported an example of $\delta$ familial arteriovenous malformation (AVM) in- $\bar{z}$ volving the brain in two sibs.

In both brother $\mathbf{G}$. and sister $\mathrm{N}$. an arteriovenous malformation of the scalp was suspected on the ground of physical findings, and this was confirmed at surgery in the former. There was no clinical o evidence of a cirsoid aneurysm in sister B., but the $N$ presence of a hole in the occipital bone in approxi- N 
mately the same location as in her siblings suggested a similar abnormality and that the lesions were familial in origin.

It is said (Olivecrona and Ladenheim, 1957) that combined extra-cranial-intracranial AVM's arise from a single embryonic maldevelopment which has failed to be split completely into layers. This concept is not in agreement with the principle of development of head vasculature in the embryo. The brain arteries (Padget 1948, 1957) are derived from the internal carotid arteries during the stage when the embryo is about 4 weeks old. The scalp arteries are derived from the external carotid arteries in a later stage when the embryo is 6 weeks old. Before this stage the thin scalp covering the membraneous skull is avascular. The dural sinuses (Streeter, 1918; Padget, 1957) are formed by the dural plexus and develop independently from the scalp and the brain vessels. The emissary veins are seen in a later stage when the embryo is 7.5 weeks old. The chondrocranium then appears around their stem and forms the emissary foramina.

On the basis of this embryological pattern it seems that there are separate origins for the scalp, dural, and cerebral congenital AVM's and when a combined extracranial-intracranial AVM occurs it is due to a secondary communication. The dural communication of the scalp AVM may develop at the same time as the emissary veins are formed and, depending on the size of the communicating vessels, the defect in the skull may vary in size as was seen in the cases reported in the present study.

\section{REFERENCES}

Amyes E. W., and Courville, C. B. (1950). Traumatic arteriovenous aneurysm of the scalp. Review of the literature and report of case. Bull. Los Angeles neurol. Soc., 15, 47-58.

Beaumont, W. M. (1897). Cirsoid aneurysm of the orbit, forehead, and scalp. Brit. med. J. 2, 273-274.
Cosman, B. (1959). Traumatic arterial malformations of the scalp: a review of the literature and two case reports. Ann. Surg., 150, 1032-1040.

Elkin, D. C. (1946). Cirsoid aneurysm of the scalp. Report of four cases. Ann. Surg., 123, 591-600.

Green. (1827-28). Aneurism of the temporal artery. Lancet, 2,381 .

Hewett, P. (1857). Aneurism by anastomoses of the left ear of a young man, treated by electric cautery. Lancet, 2 , 496-497.

Hill, J. D. (1870). On a case of aneurism by anastomosis, and the surgical means by which a cure was effected. Lancet, 2, 430-431.

Maclachlan, J. (1839). Case of extensive aneurism by anastomosis in a child ten months old, involving the branches of the temporal and pssterior auricular arteries, treated successfully by the twisted suture. Edinb. med. surg.J., 51, 357-362.

Maylard, A. E. (1900). A case of extensive cirsoid aneurysm of the scalp. Glasg. Hosp. Rep., 2, 71-75.

Moore, C. H. (1857). Case of arterio-venous aneurysm, treated by ligature of both the artery and the vein. Brit. med.J., p. 972.

Norris, G. W. (1843). Aneurism by anastomosis-ligaturecure. Amer. J. med. Sci., 5, 17.

Oldfield M. C., and Addison N. V. (1962). Cirsoid aneurysms of the scalp. Brit. med. J., 2, 23-24.

Olivecrona, H., and Ladenheim, J. (1957). Congenital Arteriovenous Aneurysms of the Carotid and Vertebral Arterial Systems. Springer: Berlin.

Padget, D. H. (1948). The development of the cranial arteries in the human embryo. Contr. Embryol. Carneg. Instn., 32, 205-261.

Padget, D. H. (1957). The development of the cranial venous system in man, from the viewpoint of comparative anatomy. Contr. Embryol. Carneg. Instn., 1, 36, 119.

Power, D'A. (1915-1916). Arterio-venous aneurysm of the left temporal artery and vein. Brit. J. Surg., 3, 297.

Streeter, G. L. (1918). The developmental alterations in the vascular system of the brain of the human embryo. Contr. Embryol. Carneg Instn., 8, 5-38.

Tonnis, W., and Lange-Cosack, H. (1953). Klinik, operative Behandlung und Prognose der arterio-venösen Angiome des Gehirns und seiner Häute; ein Bericht über 72 Fälle. Dtsch. Z. Nervenheilk., 170, 460-485.

Wacher, S. (1890). Case of cirsoid aneurysm of the scalp. Guy's Hosp. Gaz., 4, 159-161.

Ward, C. E., and Horton, B. T. (1940). Congenital arteriovenous fistulas in children. J. Pediat., 16, 746-766. 